\title{
Global-Phase H/V Spectral Ratio for Delineating the Basin in the Malargüe Region, Argentina
}

\section{by Yohei Nishitsuji, Elmer Ruigrok, Martín Gomez, and Deyan Draganov}

Online Material: Earthquake catalogs; color figures from article.

\section{INTRODUCTION}

Structural estimation of unconsolidated sediments and basins is of fundamental importance for resources exploration, geohazard assessments, and other geophysical aspects. The estimation contributes not only to the understanding of the tectonic settings, but also to the choice of parameters for possible further seismic processing, for example, predictive deconvolution, the result of which could be used for imaging the subsurface structures below the basin.

Within a number of conventional passive-seismic methodologies, the Nakamura technique (Nakamura, 1989), initially proposed for the purpose of eliminating the effect of Rayleigh waves from noise records, is widely applied. This technique can be used to estimate the resonance frequencies of the subsurface of a region of interest by taking the amplitude spectral ratio between the horizontal and vertical components $(\mathrm{H} / \mathrm{V})$ of ambient-noise records. In addition to the investigation of local site effects, if the velocity model is known, this resonance frequency can also be interpreted as the thickness of the geophysical and/ or geologic layer, characterized by relatively high-impedance contrasts on either side (Tsai, 1970). The top boundary of this layer is often the Earth's surface, whereas the lower boundary could be the interface between basement and basin. The H/V spectral ratio has been applied to estimate the depth of sedimentary boundaries and basins (e.g., Delgado et al., 2002; De Luca et al., 2005; Lane et al., 2008; Bindi et al., 2009; Ruigrok, Campman, et al., 2012).

The $\mathrm{H} / \mathrm{V}$ spectral ratio has been widely applied with ambient noise (e.g., Ohmachi et al., 1991; Field and Jacob, 1993; Lermo and Chavez Garcia, 1993), as well as with arrivals from earthquake records (e.g., Lermo and Chavez Garcia, 1993; Field and Jacob, 1995; Ferretti et al., 2007; Grecu et al., 2011; Ruigrok, Campman, et al., 2012), because of its stability and its relatively simple application procedure. Lermo and Chavez Garcia (1993) and Field and Jacob (1995), for example, have applied the H/V spectral ratio to $S$ waves from local-earthquake records and the resonant frequencies have been successfully identified. With $P$ waves from local earthquakes, $\mathrm{Ni}$ et al. (2014) lately succeeded in estimating the shear-wave velocity.
In a recent work, Ruigrok, Campman, et al. (2012) extended the epicentral distance of earthquakes using a single teleseismic earthquake, and several resonance frequencies were clearly identified. Ferretti et al. (2007) used a wide range of epicentral distances from $41^{\circ}$ to $185^{\circ}$ by selecting 18 earthquakes. To this date, studies have not applied the $\mathrm{H} / \mathrm{V}$ spectral ratio exclusively to recordings of global phases. Global phases are the arrivals from distant earthquakes (epicentral distance $\geq 120^{\circ}$ ) that traverse the core before reaching the receivers; their ray parameters are smaller than $0.04 \mathrm{~s} / \mathrm{km}$ for $P$-wave phases. The amplitude spectra derived from the $\mathrm{H} / \mathrm{V}$ spectral ratio are commonly interpreted as the resonance spectra for vertically propagating body waves (e.g., Field and Jacob, 1995). Global phases have a near vertical incidence. Hence, the resonance spectra derived from global phases could straightforwardly be interpreted.

In the following, we apply the global phase $\mathrm{H} / \mathrm{V}$ spectral ratio, which hereafter is abbreviated as GloPHV, to data recorded by the Malargüe seismic array (MalARRgue; Ruigrok, Draganov, et al., 2012) in the Malargüe region, Mendoza, Argentina, to delineate a part of the local structure of the Malargüe basin.

\section{MALARRGUE}

MalARRgue recorded continuous seismic waveforms from January 2012 to January 2013. It was located between longitudes $68.25^{\circ} \mathrm{W}$ and $70.50^{\circ} \mathrm{W}$ and latitudes $34.75^{\circ} \mathrm{S}$ and $35.50^{\circ} \mathrm{S}$, about $250 \mathrm{~km}$ east of the Maule Region in Chile (Fig. 1), infamous because of the Maule earthquake (27 February $2010 M_{\mathrm{w}} 8.8$,). (E) Figure S1 is available as the color version of Figure 1 in an electronic supplement. The array contained two areal subarrays: P array (black squares in Fig. 1), situated on the eastern flank of the Peteroa Volcano; and T array, situated on a high plateau east of the Andes. The T array itself was composed of two linear subarrays: the TN array (white triangles in Fig. 1) had 19 stations labeled TN-2 to TN-20 deployed every $2 \mathrm{~km}$ in the south-southeast-northnorthwest direction with $\mathrm{TN}-2$ the southernmost station. The TE array (black triangles in Fig. 1) had 13 stations labeled TE-1 to TE-13 deployed at about $4 \mathrm{~km}$ spacing in the westsouthwest-east-northeast direction with TE-1 the westernmost station. All stations recorded three orthogonal components of particle velocity (vertical, north, and east). MalARRgue used mainly $2 \mathrm{~Hz}$ sensors (Sercel L-22) borrowed from the 


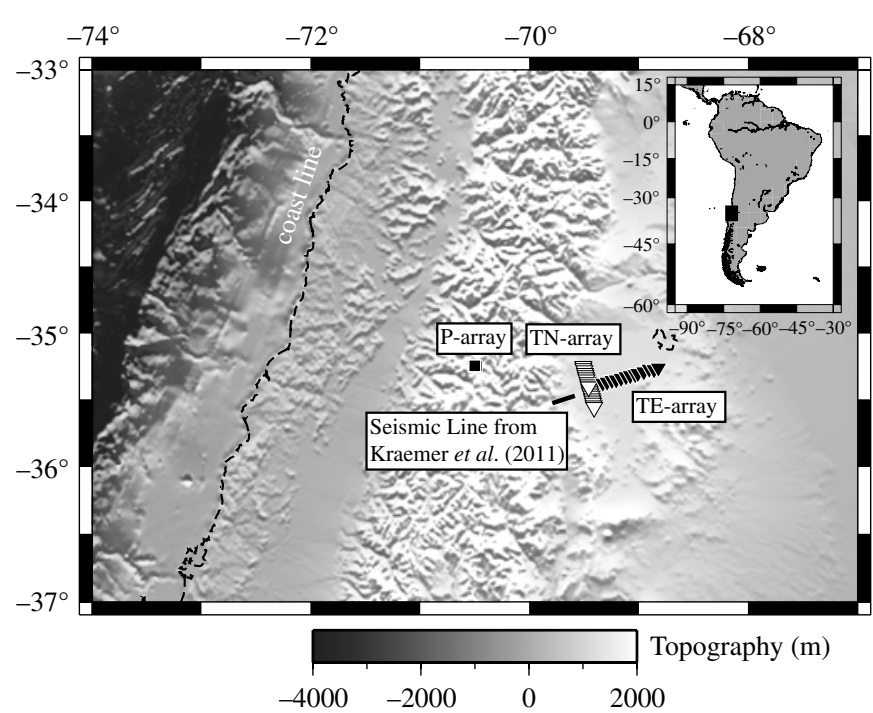

A Figure 1. Topography map of the study region. The topography data is adapted from Becker et al. (2009). The white and black triangles depict the locations of the seismic stations of the TNand TE-subarrays of the Malargüe seismic array. The black squares show the location of the $P$-array stations. The black line indicates the location at which an active-source seismic section is obtained in Kraemer et al. (2011).

Incorporated Research Institutions for Seismology-Program for Array Seismic Studies of the Continental Lithosphere (IRIS-PASSCAL). In the current study, we use the data from the $\mathrm{T}$ array.

The two lines of the T-array recorded arrivals with a wide range of epicentral distances starting from local and regional seismicity (because of their proximity to the Nazca subduction zone) and going to teleseismic and global phases (related to their alignment with large transects of the Ring of Fire). The illumination characteristics of the linear subarrays for structural imaging, but also other details about MalARRgue, can be found in Ruigrok, Draganov, et al. (2012), for example, figure 3 in their article.

Strollo et al. (2008) previously evaluated the suitability of a $2 \mathrm{~Hz}(\mathrm{~L}-22), 1 \mathrm{~Hz}$, and other short-period sensors for the $\mathrm{H} /$ $\mathrm{V}$ spectral ratio using ambient-noise records as input data. The authors concluded that the $2 \mathrm{~Hz}$ and $1 \mathrm{~Hz}$ sensors could be used at least down to 0.3 and $0.2 \mathrm{~Hz}$, respectively. The reliability lower than these frequencies would depend on the magnitude (amplitude) level of the input data. MalARRgue also contained one $0.033 \mathrm{~Hz}$ (Güralp 40T) reference sensor, named TN-99, which was collocated with station TN-11, which had a $2 \mathrm{~Hz}$ (L-22) sensor. Comparing GloPHV from earthquakes with $M_{\mathrm{w}} \geq 5.5$, which show clearly higher amplitudes than the ambient noise, calculated for TN-11 and TN-99 (Fig. 2), we see that the ratios are similar in shape, but not in amplitude down to $1 \mathrm{~Hz}$. The peaks and troughs remain at the same frequencies down to around $0.2 \mathrm{~Hz}$. For values lower than that frequency, the tendencies of the ratios start to differ, see, for example, the black arrows in Figure 2. Therefore, we limit our analysis to frequencies down to $0.15 \mathrm{~Hz}$, with the notion that

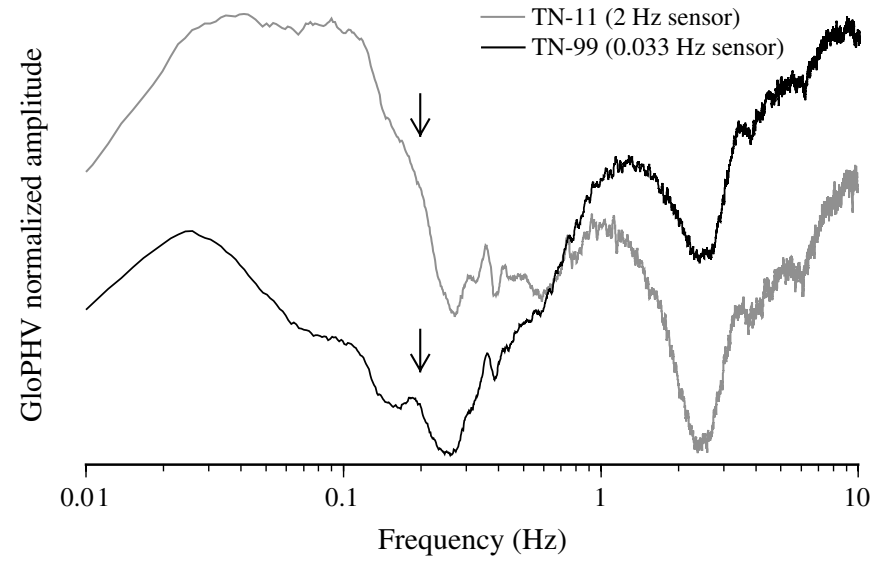

- Figure 2. Comparison of GloPHV between the TN-11 station (with a $2 \mathrm{~Hz}$ sensor) and the TN-99 (with a $0.33 \mathrm{~Hz}$ sensor) reference station. The black arrows indicate the frequency of $0.2 \mathrm{~Hz}$, below which the two ratios start exhibiting differing trends.

only the very large features may be interpreted at the lower end of this band.

Because we are targeting to delineate the Malargüe basin using the fundamental resonance frequency, we limit our band for interpretations to a maximum frequency of $2.5 \mathrm{~Hz}$.

\section{MALARGÜE BASIN}

The Malargüe basin is Permo-Triassic age and is quasisedimentary. It is a subbasin in the Neuquén basin (e.g., Witte and Periale, 2008). It has been producing about $44 \%$ of the Argentinian oil and has a promising potential of unconventional resources (e.g., shale gas). It is located in the eastern part of the Andes, between $35^{\circ} \mathrm{S}$ and $37^{\circ} \mathrm{S}$ latitude, forming an elongated structure in the north-south direction at the eastern side of the Malargüe anticline. Witte and Periale (2008) reported that the Neuquén basin is thinning to the east. Because of this, the Malargüe basin is likely to be thinning toward the east. Kraemer et al. (2011) studied the geometry and evolution of the Andean fold and thrust belt in the location situated to the southwest from MalARRgue. Their results show that the depth of the depocenter and the western part of the Malargüe basin, widely being covered by more than $2 \mathrm{~km}$ of Tertiary sediments, would be around 5.5 to $6.0 \mathrm{~km}$ from the acquisition (Earth) surface. Their imaged seismic section, obtained from recordings from active sources (location shown in Fig. 1 with the black line), with the stratigraphic interpretations in their article shows that the basin becomes shallower toward the east, that is, toward the location of the T array from MalARRgue. Because the active seismic section does not pass through our study region, the depth of the Malargüe basin under the T array is not known.

\section{GLOBAL PHASES}

For the purpose of obtaining GloPHV, we extract from the recordings windows with length of $600 \mathrm{~s}$, starting $5 \mathrm{~s}$ before the first $P$-wave phase $(P K I K P)$ or $S$-wave phase arrival, from 


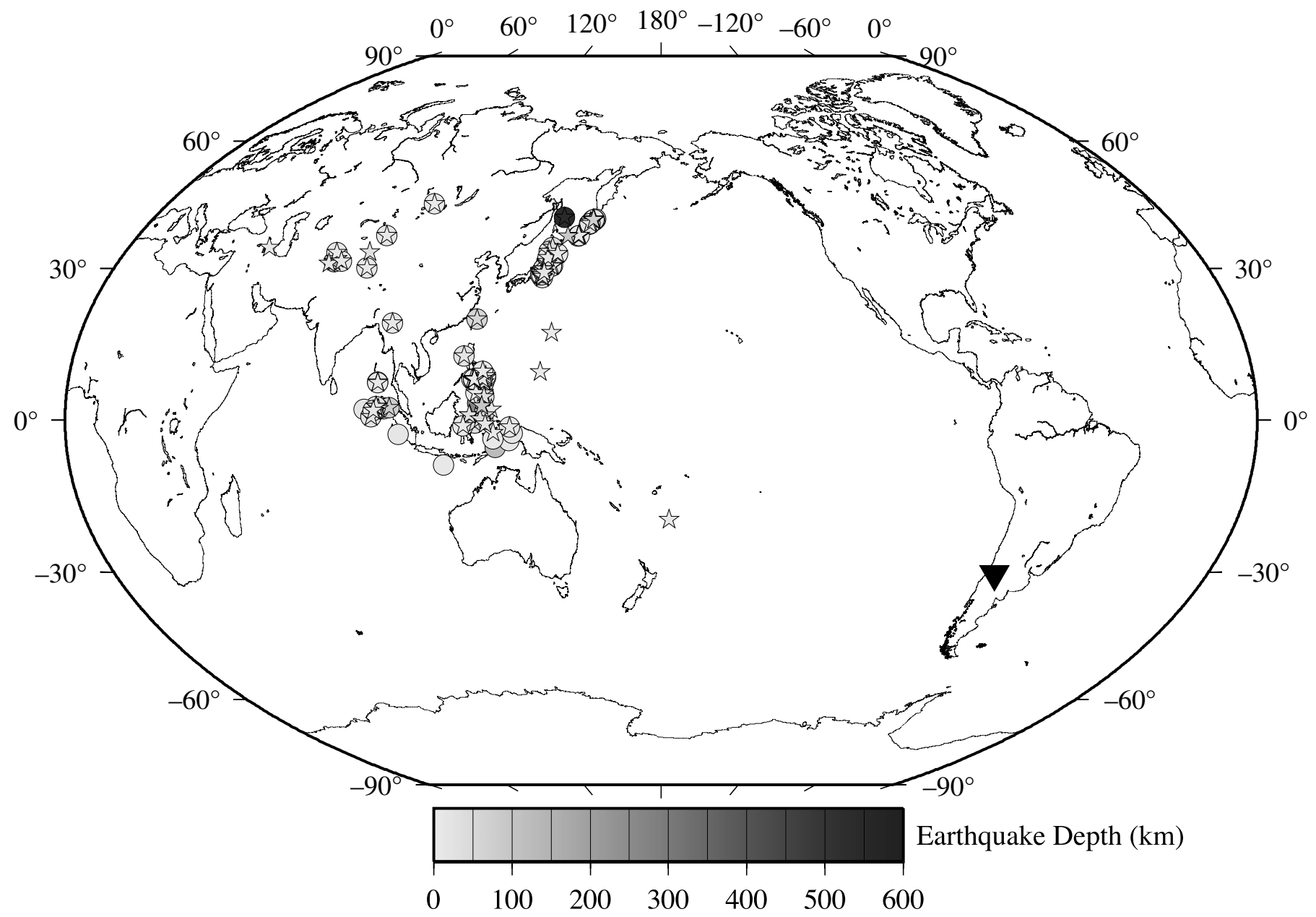

A Figure 3. Distribution map of the global earthquakes (epicentral distance $\geq 120^{\circ}$ ) with $M_{\mathrm{w}} \geq 5.5$ used in our study. The 69 circles and 79 stars show the location of the earthquakes used for the TN- and TE array, respectively, gray scaled as a function of their focal depth. The location of the Malargüe seismic array is indicated by the black triangle.

earthquakes with epicentral distances larger than $120^{\circ}$ (see Fig. 3). (E) Figure $S 2$ is available as the color version of Figure 3 in the electronic supplement. In the following, we refer to the aforementioned window as the $P$ window or $S$ window, respectively. We extract these windows using Java version of Windows Extracted from Event Data (JWEED) from IRIS. Based on the earthquake catalog from the U.S. Geological Survey (USGS, http://earthquake.usgs.gov/earthquakes/; last accessed December 2013), we select 69 global earthquakes for the TN array (shown as circles in Fig. 3) and 79 global earthquakes for the TE array (shown as stars in Fig. 3) with $M_{\mathrm{w}} \geq 5.5$. (E) A complete listing of the used earthquakes is given in Table S1. Because of the $600 \mathrm{~s}$ window duration, the recordings from each earthquake will contain several global phases and a few teleseismic phases, such as PPP. The time window for each of the earthquakes is individually determined using a function of JWEED and a ray-tracing model (Knapmeyer, 2004) based on iasp91 (Kennett and Engdahl, 1991). The $P$ window is dominated by $P$-wave phases, such as $P K P$, $P K i K P$, and PKIKP. Similarly, the $S$ window is dominated by $S$-wave phases, such as $S K S, S K K S$, and $S K K K S$, but also has a few $P$-wave phase arrivals, such as $P K P P C P$ and $P P P$. The predominant ray parameters, often called horizontal slowness as well, for the $P$-wave phases and the $S$-wave phases would be smaller than 0.04 and $0.076 \mathrm{~s} / \mathrm{km}$, respectively.

We visually inspect the chosen windows to make sure that they contain global phases only from a single earthquake. Recordings with high pre-event noise levels, due to the microseism, anthropogenic noise, but also due to regional and/or local seismicity, were not used (Fig. 3 shows only the earthquakes that were actually used).

\section{GLOBAL-PHASE H/N SPECTRAL RATIO (GloPHV)}

We assume the global phases are nearly vertically incident at the receivers and have no predominant resonance frequency within our frequency band of interest, prior to interaction with the crust below the receivers. Moreover, we assume that the illuminating wavefront contains only $P$-wave phases for the $P$ window. In this case, the observed amplitude spectra for vertical and horizontal components can be written as (e.g., Field and Jacob, 1995; Ruigrok, Campman, et al., 2012) 
$\left|\hat{O}^{V}\left(\mathbf{X}_{R}\right)\right|=\left|\hat{E} \hat{G}^{P}\left(\mathbf{X}_{B}, \mathbf{x}_{S}\right) \hat{L}^{P}\left(\mathbf{X}_{R}, \mathbf{x}_{B}\right) \hat{I}\left(\mathbf{X}_{R}\right)\right|$

and

$\left|\hat{O}^{H}\left(\mathbf{X}_{R}\right)\right|=\left|\hat{E} \hat{G}^{P}\left(\mathbf{X}_{B}, \mathbf{x}_{S}\right) \hat{L}^{S}\left(\mathbf{X}_{R}, \mathbf{x}_{B}\right) \hat{I}\left(\mathbf{X}_{R}\right)\right|$,

in which $\hat{O}$ is the observed amplitude spectrum; $\hat{E}$ is the spectrum of the source function of the global phases; $\hat{G}\left(\mathbf{X}_{B}, \mathbf{x}_{S}\right)$ is the Green's function (path effect) between the source $\mathbf{x}_{S}$ and the top of the basement $\mathbf{X}_{B} ; \hat{L}\left(\mathbf{X}_{R}, \mathbf{x}_{B}\right)$ is the local site effect between the top of the basement and the receiver $\mathbf{X}_{R}$. The expression $\hat{I}\left(\mathbf{X}_{R}\right)$ is the instrument response; the hats indicate that the quantities are in the frequency domain; superscripts $V$ and $H$ denote the vertical and the horizontal component, respectively; and superscripts $P$ and $S$ denote $P$ and $S$ waves, respectively. The time window does not contain $S$-wave phases. Hence, we assume that the horizontal-component recording (equation 2) contains primarily $P$-to- $S$ converted waves. Because we select to use data from earthquakes with large epicentral distances $\left(\geq 120^{\circ}\right)$, the wave front at the stations is practically planar. For most distances, the corresponding ray parameters are still sufficiently large for converted waves to occur. GloPHV is obtained by the spectral division from equations (1) and (2):

$$
\begin{aligned}
\text { GloPHV } & =\left|\hat{O}^{H}\left(\mathbf{X}_{R}\right)\right| /\left|\hat{O}^{V}\left(\mathbf{X}_{R}\right)\right| \\
& \approx\left|\hat{L}^{S}\left(\mathbf{X}_{R}, \mathbf{x}_{B}\right)\right| /\left|\hat{L}^{P}\left(\mathbf{X}_{R}, \mathbf{x}_{B}\right)\right| .
\end{aligned}
$$

On the other hand, for the $S$ window, we assume that the observed amplitude spectra for vertical and horizontal components are dominant by $P$-wave phases (e.g., $P P P)$ and $S$-wave phases (e.g., $S K S$ ), respectively. Then, the observed amplitude spectra for vertical and horizontal components can be written as

$$
\left|\hat{O}^{V}\left(\mathbf{X}_{R}\right)\right|=\left|\hat{E} \hat{G}^{P}\left(\mathbf{X}_{B}, \mathbf{x}_{S}\right) \hat{L}^{P}\left(\mathbf{X}_{R}, \mathbf{x}_{B}\right) \hat{I}\left(\mathbf{X}_{R}\right)\right|
$$

and

$\left|\hat{O}^{H}\left(\mathbf{X}_{R}\right)\right|=\left|\hat{E} \hat{G}^{S}\left(\mathbf{X}_{B}, \mathbf{x}_{S}\right) \hat{L}^{S}\left(\mathbf{X}_{R}, \mathbf{x}_{B}\right) \hat{I}\left(\mathbf{X}_{R}\right)\right|$.

Clearly, the paths effects for $P$-wave phases are very different from $S$-wave phases and hence $G^{P} \neq G^{S}$. However, possible resonance frequencies in $\left|\hat{G}^{P}\right|$ and $\left|\hat{G}^{S}\right|$, such as the one from the D-double-prime layer, should result in much lower frequency than our band of interest $(0.15-2.5 \mathrm{~Hz})$. Hence, we assume that, in the frequency band of interest, $\left|\hat{G}^{P}\right|=a\left|\hat{G}^{S}\right|$, in which $a$ is a frequency independent scaling factor. Dividing equation (5) by equation (4), using the above assumption and assuming that for a distant earthquake $\hat{E}$ is the same for the $P$ - and $S$-wave phases (or they are related by a frequency independent scaling factor), we find a scaled version of equation (3). Besides resonances from the crustal layers below the receivers, computing equation (3) for a single earthquake might result in resonances from the layers near the source. For this reason, only after averaging GloPHV over multiple earthquakes, the incoherent source-side resonances are suppressed, which allows interpretation of the averaged GloPHV for the receiver-side structure. Each of the time windows we use for implementing equation (3) contains multiple phases in practice. Overlapping reverberations from different phases can lead to spurious resonances. The delay times between the phases vary with earthquake (distance). Hence the spurious phase cross terms are also suppressed by averaging GloPHV over multiple earthquakes.

Equation (3) allows isolating the resonance spectra of the basin from the observed waveforms. The resonance frequencies for $P$ or $S$ waves $\left|\hat{L}^{P}\left(\mathbf{X}_{R}, \mathbf{x}_{B}\right)\right|$ or $\left|\hat{L}^{S}\left(\mathbf{X}_{R}, \mathbf{x}_{B}\right)\right|$, lead to troughs or peaks because they are in the denominator or numerator in equation (3), respectively. We take the root mean square of the north and east components to obtain the value of the horizontal component (e.g., Ferretti et al., 2007; Lane et al., 2008). According to Tsai (1970) and Ibs-von Seht and Wohlenberg (1999), for example, the fundamental resonance frequency, a part of $\hat{L}\left(\mathbf{X}_{R}, \mathbf{x}_{B}\right)$, can be written as

$f_{0}^{P, S}=\frac{1}{T_{0}^{P, S}}=\frac{V^{P, S}}{4 Z}$,

in which $f_{0}^{P, S}$ is the resonance frequency for a $P$ - or $S$ wave, $T_{0}^{P, S}$ is the resonance period, $V^{P, S}$ is the velocity of a $P$ - or $S$ wave, and $Z$ is the thickness of a layer. This equation can be used to estimate the depth to a seismic boundary from the resonance frequency. The resonance frequency $f_{0}^{P}$ of the $P$ wave should be higher than the resonance frequency $f_{0}^{S}$ of the $S$ wave, when the two are a resonance from the same structure.

The data processing procedure is as follows. First, using JWEED, we extract the $600 \mathrm{~s}$ windows for each of the three

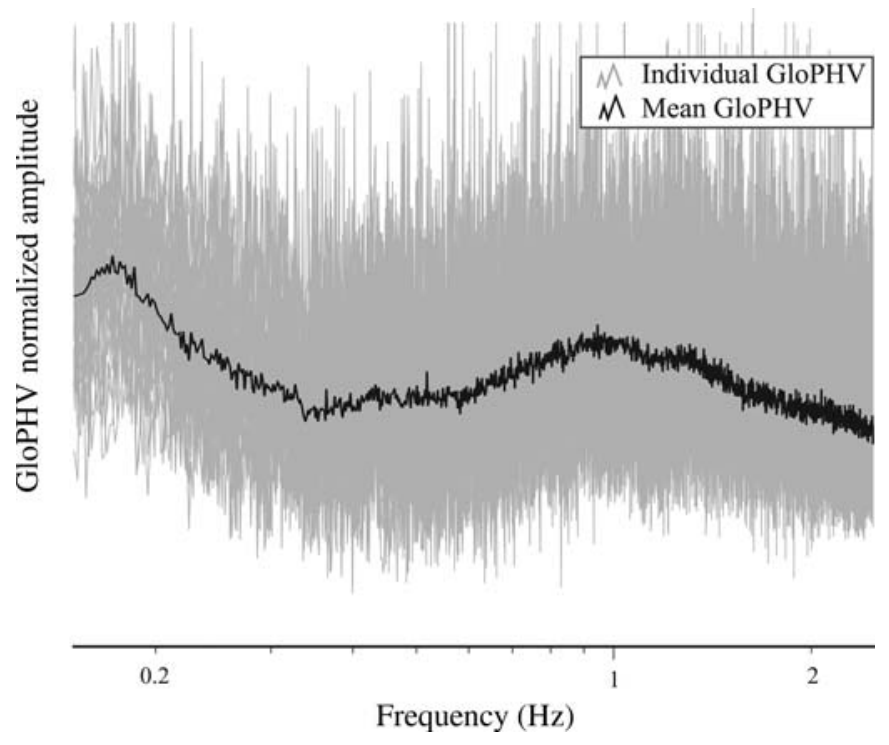

- Figure 4. Example of the 79 individual GloPHVs (gray) and the mean GloPHV (black) for station TE-1, the westernmost station of the TE array. The mean GloPHV is shown before application of the moving average from the postprocessing. 
components for all chosen earthquakes. For each of the windows, we remove the mean level. Then, running absolute-mean normalization is applied with a $10 \mathrm{~s}$ running window to make the different global phases of the same order and to boost the amplitudes of the $P$ - and $S$-wave reverberations with respect to the otherwise dominating direct arrivals. Subsequently, using 10 per cent tapering, a fast Fourier transform was applied. Then, we obtain GloPHV for each station of the TN- and the TE arrays from the chosen 69 and 79 global earthquakes, respectively. Finally, for each station we take the mean GloPHV from all global phases at that station. As a postprocessing step, we apply a moving average (low-pass filtering) to ease the identification of the dominant resonance frequencies and subsequently we normalize the amplitudes. An example of the mean GloPHV after the moving average for the station TE1 from the TE array is shown in Figure 4 in black; the 79 individual contributions to the mean result are shown in gray in the figure.

\section{RESULTS AND DISCUSSION}

The mean and amplitude-normalized GloPHVs for each station from the TN array of MalARRgue from the $P$ and $S$ windows are shown in Figure $5 \mathrm{a}$ and $5 \mathrm{~b}$, respectively. The analogous results for the TE array are shown in Figure $5 c, d$ with filled peaks for ease of interpretation. Although there are small differences present in the particulars for each mean GloPHV, the features of the fundamental resonance frequency

\section{GloPHV for TN-array}

(a)

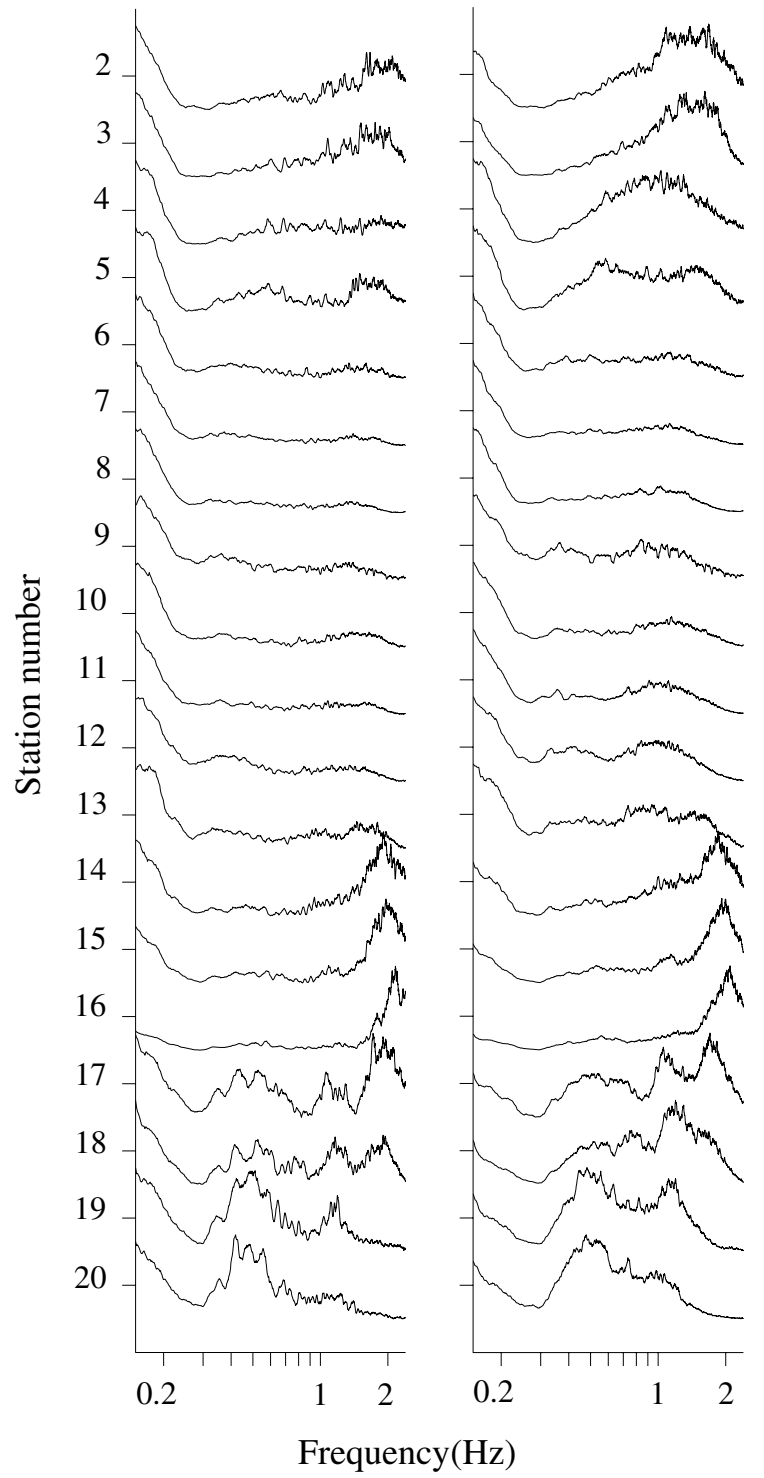

(c)

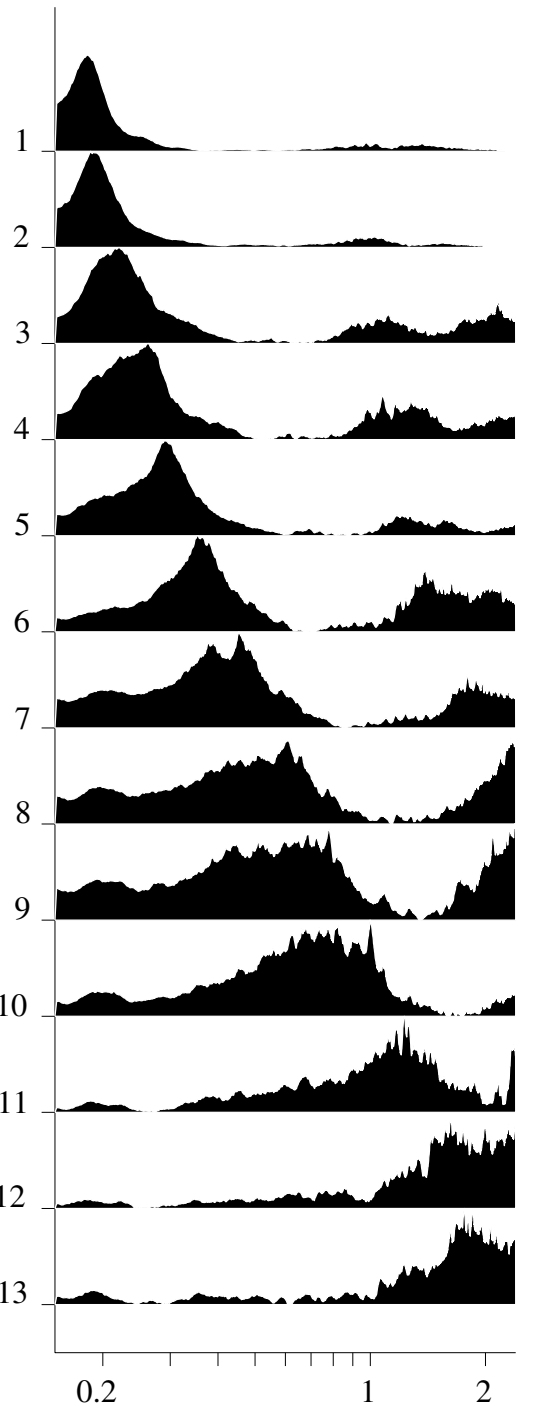

(d)

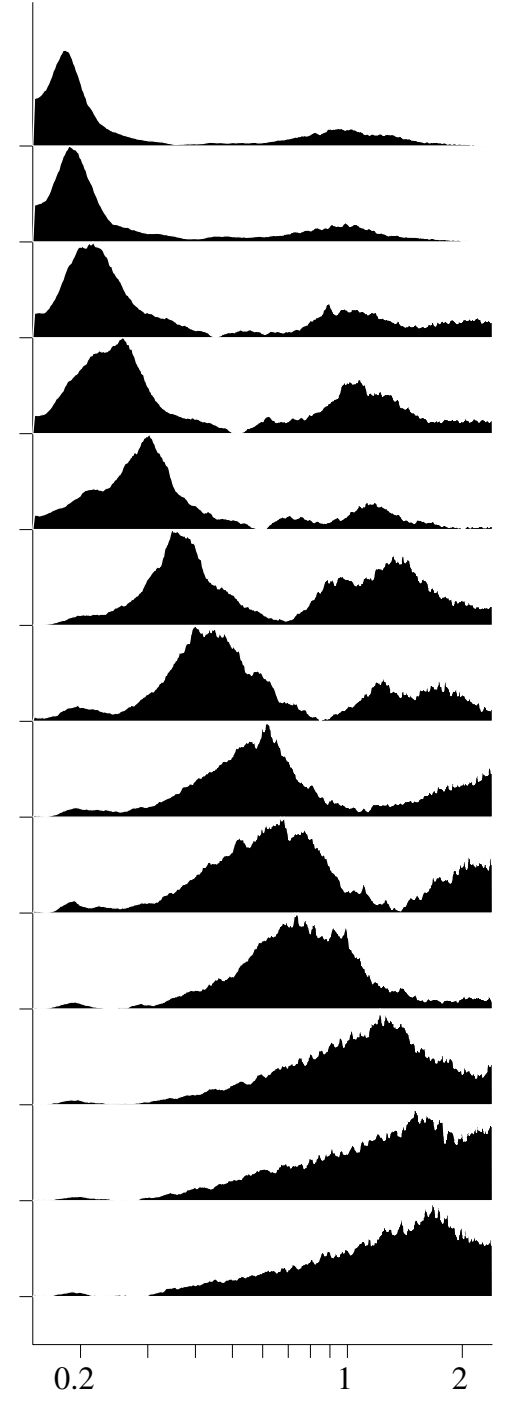

Frequency $(\mathrm{Hz})$

- Figure 5. GloPHV results for: TN array from (a) the $P$ window; (b) the $S$ window; and TE array from (c) the $P$ window; (d) the $S$ window. The individual spectra are sorted as a function of the station number. The peaks for TE array are filled in black. 
show very good similarity between Figure $5 \mathrm{a}$ and $5 \mathrm{~b}$, and between Figure $5 \mathrm{c}$ and $5 \mathrm{~d}$. Because the fundamental resonance frequencies using the $S$ window show somewhat clearer results (e.g., TN-4, TN-5, TE-7, and TE-8), hereafter we use the results shown in Figure 5b,d.

Looking at the fundamental resonance frequency for the TN array in Figure 5b, we see that it is difficult to identify the related peaks (corresponding to the $S$-wave resonances) around $0.15 \mathrm{~Hz}$ probably due to our choice of using $0.15 \mathrm{~Hz}$ as a lowfrequency limit. On the other hand, the troughs (corresponding to the $P$-wave resonances) are fairly easily identifiable around $0.25 \mathrm{~Hz}$. For the TE array results in Figure $5 \mathrm{~d}$, we can see that fundamental peaks can be clearly identified (e.g., the peak around $0.2 \mathrm{~Hz}$ for TE-2). These peaks can be identified for all of the TE-array stations and appear to be shifting toward higher frequency with increasing station number (from the TE-1 to TE-13). The troughs for the TE array are also identifiable, but generally less clearly.

In Figure 6a,b, we show the fundamental resonance periods $(1 / \mathrm{Hz})$ at each station as a function of distance from the station with the lowest station number for each subarray obtained using the troughs for the TN array and the peaks for the TE array. For clarity, above each period in Figure 6a,b we also
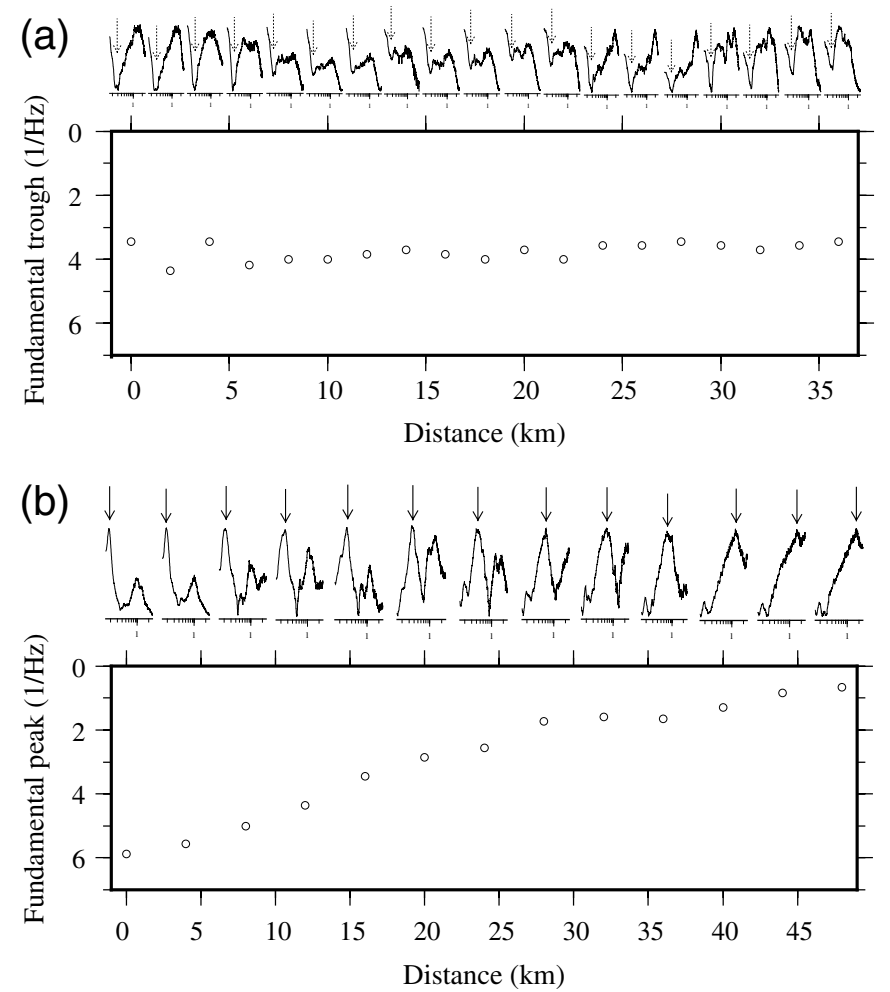

A Figure 6. Fundamental resonant periods obtained from GloPHV for: (a) TN array results in Figure $5 b$ as a function of the distance from station TN-2 (south-southeast-north-northwest); (b) TE array results in Figure $5 \mathrm{~d}$ as a function of distance from station TE- 1 (west-southwest-east-northeast). Above each station position is shown the station's spectrum from Figure 5 with the used trough or peak. show GloPHV of the corresponding station with the fundamental troughs or peaks between 0.15 and $2.5 \mathrm{~Hz}$ indicated by dashed or solid arrows, respectively.

Following the work of Farías et al. (2010) for central Chile, we assume average values of the $P$ - and $S$-wave velocity through the basin of 5.2 and $2.9 \mathrm{~km} / \mathrm{s}$, respectively. Thereby, we convert the periods from Figure $6 \mathrm{a}, \mathrm{b}$ to the estimated depth of the bottom of the Malargüe basin using only the average $P$ - and only the average $S$-wave velocity, respectively. We show the respective results in Figure 7a,b. Below the TN array, the basin's bottom (basement's top) is at about $5 \mathrm{~km}$ depth. We can also see that there is a shallowing trend of the basin's bottom in the north-northwest direction. Under the TE array, the basin's bottom shows clear shallowing trend from west to east going from a depth of $4 \mathrm{~km}$ to a depth of $0.5 \mathrm{~km}$.

MalARRgue's T array is about $10 \mathrm{~km}$ to the east from the arrays Kraemer $e t$ al. (2011) used to obtain their active-source seismic section. In their seismic section, the depocenter (the basin's center) is at depth of about 5.5 to $6 \mathrm{~km}$ and there is a clear shallowing trend in the east direction. Extrapolation of their results to the $T$ array would mean a good agreement with the depths we obtain from GloPHV taking into account the possible variations of the depths due to uncertainties in the assumed velocities.
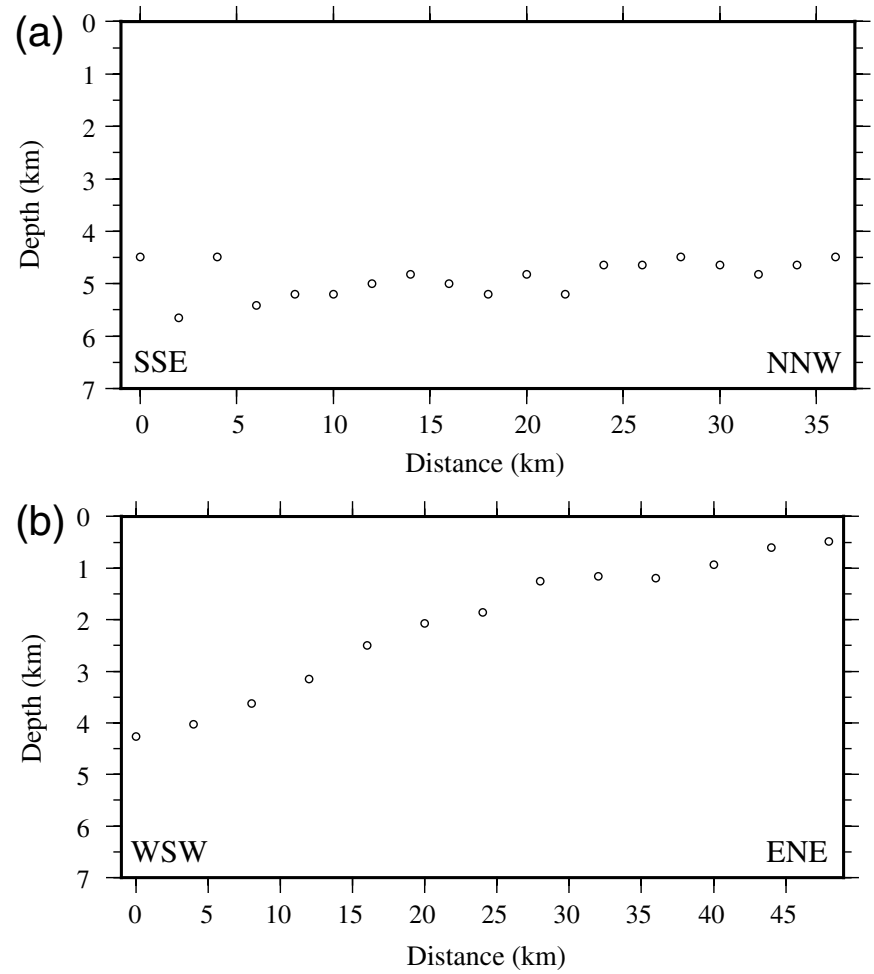

A Figure 7. Estimated depth of the bottom of the Malargüe basin derived from the fundamental periods from Figure 6: (a) below the TN array as a function of the distance from station TN-2 using an average $P$-wave velocity of $5.2 \mathrm{~km} / \mathrm{s}$; (b) below the TE array as a function of the distance from station TE-1 using an average $S$-wave velocity of $2.9 \mathrm{~km} / \mathrm{s}$. 


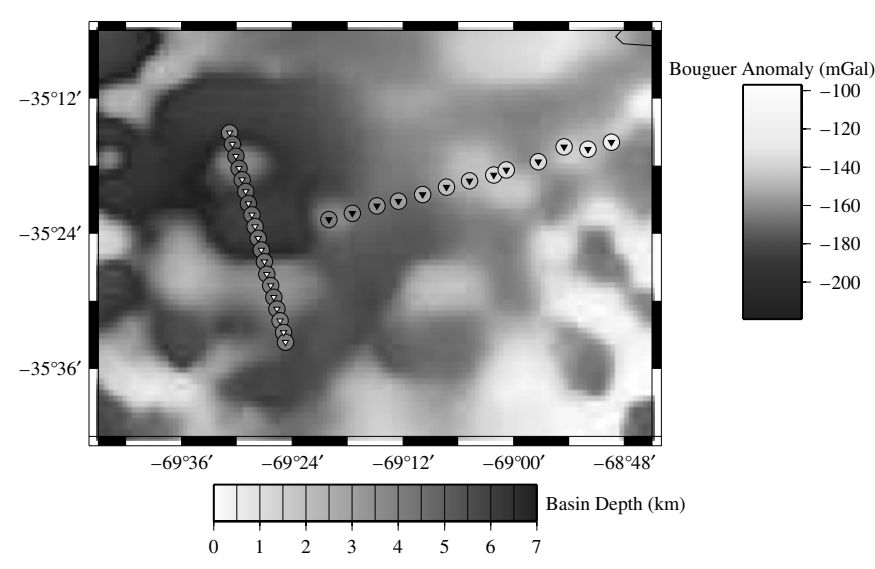

A Figure 8. Map of the Bouguer gravity anomaly, obtained from the Bureau Gravimétrique International (BGI), around the T array. The white and black triangles indicate the positions of the seismic stations as in Figure 1. The estimated depth of the bottom of the basin is depicted by the gray-scale circles.

There are also other peaks and troughs in GloPHV results at frequencies higher than the fundamental resonance frequency, which could be related to the depths to sedimentary boundaries inside the basin. Because our interest is determining the depth to the bottom of the basin, we do not interpret sedimentary boundaries in this study.

To further evaluate the accuracy of the estimated depth to the top of the basement we obtained from GloPHV, we compare our results to a Bouguer-anomaly map. The Bouguer gravitational anomaly is often used in petroleum exploration to estimate the location of basins. In Figure 8, we show the Bouguer anomaly map around MalARRgue, which we took from the Bureau Gravimétrique International (BGI, http://bgi .obs-mip.fr; last accessed October 2013). (E) Figure S3 is available as the color version of Figure 8 in the electronic supplement. On the anomaly, we overlay the $T$ array (the triangles) with the estimated depths depicted by the gray-scale circles around each station. Lower values for the Bouguer anomaly indicate thickening of the basin, whereas higher values indicate thinning of the basin. Very good agreement exists between the basin's bottom structure we obtain and the gravity anomalies, implying that GloPHV is effective to estimate the depth of the basin using the fundamental resonance frequencies.

\section{CONCLUSION}

We proposed to use phases from distant earthquakes, such as $S K S$, SKKS, SKKKS, PKP, and PKPPCP, for the H/V spectralratio method to identify the fundamental resonance frequencies of receiver-side structure. We demonstrated this method using data recorded in the Malargüe region, Mendoza, Argentina. We showed that the method is little sensitive to the mix of phases that is used as an input. Both with time windows with merely $P$-wave phases (and converted energy on the horizontal component) and with time windows with mixed phases, the same resonance frequencies were found. However, the $\mathrm{H} / \mathrm{V}$ spectral ratio had to be stacked over many $(>10)$ earthquakes to suppress source-side resonances and phase cross terms. From the extracted fundamental resonance frequencies, we delineated the bottom of part of the Malargüe basin. Comparison with active-source seismic profile, recorded in the past close to our study region, and with the Bouguer gravity anomaly of the region, shows a very good agreement with the delineated structure. This suggests reliable applicability of our method. $\mathbf{\Sigma}$

\section{ACKNOWLEDGMENTS}

This research is supported by the Division for Earth and Life Sciences (ALW) with financial aid from the Netherlands Organization for Scientific Research (NWO) with Grant VIDI 864.11.009. This research is also supported by the Netherlands Research Centre for Integrated Solid Earth Sciences (ISES). We thank Incorporated Research Institutions for Seismology-Program for Array Seismic Studies of the Continental Lithosphere (IRIS-PASSCAL) for providing the seismic equipment and the Argentine Ministry of Science, Technology, and Production Innovation for the financial support connected to the transportation of the equipment. We also thank Pierre Auger and the department of Civil Defense of Malargüe for the help during the data acquisition. Seismic Analysis Code (SAC2000) was used for a part of data processing. The maps and graphs were drawn with the Generic Mapping Tool (GMT).

\section{REFERENCES}

Becker, J. J., D. T. Sandwell, W. H. F. Smith, J. Braud, B. Binder, J. Depner, D. Fabre, J. Factor, S. Ingalls, S.-H. Kim, R. Ladner, K. Marks, S. Nelson, A. Pharaoh, R. Trimmer, J. Von Rosenberg, G. Wallace, and P. Weatherall (2009). Global bathymetry and elevation data at 30 arc seconds resolution: SRTM30_PLUS, Mar. Geodes. 32, 355-371.

Bindi, D., S. Marzorati, S. Parolai, A. Strollo, and K. H. Jäkel (2009). Empirical spectral ratios estimated in two deep sedimentary basins using microseisms recorded by short-period seismometers, Geophys. J. Int. 176, doi: 10.1111/j.1365-246X.2008.03958.x.

Delgado, J., P. Alfaro, J. Galindo-Zaldivar, A. Jabaloy, A. C. López Garrido, and C. Sanz De Galdeano (2002). Structure of the PadulNigüelas basin (S Spain) from H/V ratios of ambient noise: Application of the method to study peat and coarse sediments, Pure Appl. Geophys. 159, 2733-2749.

De Luca, G., S. Marcucci, G. Milana, and T. Sanò (2005). Evidence of low-frequency amplification in the city of L'Aquila, central Italy, through a multidisciplinary approach including strong- and weakmotion data, ambient noise, and numerical modelling, Bull. Seismol. Soc. Am. 95, 1469-1481.

Farías, M., D. Comte, R. Charrier, J. Martinod, C. David, A. Tassara, F. Tapia, and A. Fock (2010). Crustal-scale structural architecture in central Chile based on seismicity and surface geology: Implications for Andean mountain building, Tectonics 29, TC3006, doi: 10.1029/2009TC002480.

Ferretti, G., M. Massa, L. Isella, and C. Eva (2007). Site-amplification effects based on teleseismic wave analysis: The case of the Pellice valley, Piedmont, Italy, Bull. Seismol. Soc. Am. 97, 605-613.

Field, E., and K. Jacob (1993). The theoretical response of sedimentary layers to ambient seismic noise, Geophys. Res. Lett. 20, 2925-2928.

Field, E. H., and K. H. Jacob (1995). A comparison and test of various site response estimation techniques, including three that 
are non reference-site dependent, Bull. Seismol. Soc. Am. 85, $1127-1143$.

Grecu, B., V. Raileanu, A. Bala, and D. Tataru (2011). Estimation of site effects in the eastern part of Romania of the basis of $\mathrm{H} / \mathrm{V}$ ratios of $S$ and coda waves generated by Vrancea intermediate-depth earthquakes, Rom. J. Phys. 56, 563-577.

Ibs-von Seht, M., and J. Wohlenberg (1999). Microtremor measurements used to map thickness of soft sediments, Bull. Seismol. Soc. Am. 89, 250-259.

Kennett, B. L. N., and E. R. Engdahl (1991). Traveltimes for global earthquake location and phase identification, Geophys. J. Int. 122, 429-465.

Knapmeyer, M. (2004). TTBox: A MATLAB toolbox for the computation of 1D teleseismic travel times, Seismol. Res. Lett. 75, 726-733, doi: $10.1785 /$ gssrl.75.6.726.

Kraemer, P., J. Silvestro, F. Achilli, and W. Brinkworth (2011). Kinematics of a hybrid thick-thin-skinned fold and thrust belt recorded in Neogene syntectonic wedge-top basins, southern central Andes between $35^{\circ}$ and $36^{\circ} \mathrm{S}$, Malargüe, Argentina, AAPG Memoir 94, 245-270.

Lane, J. W., E. A. White, G. V. Steele, and J. C. Cannia (2008). Estimation of bedrock depth using the horizontal-to-vertical (H/V) ambient-noise seismic method, paper presented at Symposium on the Application of Geophysics to Engineering and Environmental Problems, Philadelphia, Pennsylvania, 6-10 April 2008.

Lermo, J., and F. J. Chavez-Garcia (1993). Site effect evaluation using spectral ratios with only one station, Bull. Seismol. Soc. Am. 83, $1574-1594$.

Nakamura, Y. (1989). A method for dynamic characteristics estimation of subsurface using microtremor on the ground surface, Q. Rep. Railway Tech. Res. Inst. 30, 25-30.

$\mathrm{Ni}, \mathrm{S}$., Z. Li, and P. Somerville (2014). Estimating subsurface shear velocity with radial to vertical ratio of local $P$ waves, Seismol. Res. Lett. 85, 82-90, doi: 10.1785/0220130128.

Ohmachi, T., Y. Nakamura, and T. Toshinawa (1991). Ground motion characteristics in the San Francisco Bay area detected by microtremor measurements, paper presented at the Second International Conference on Recent Advances in Geotechnical Earthquake Engineering and Soil Dynamics, University of Missouri, Rolla, 11-15 March 1991.
Ruigrok, E., X. Campman, and K. Wapenaar (2012). Basin delineation with a 40-hour passive seismic record, Bull. Seismol. Soc. Am. 102, 2165-2176, doi: 10.1785/0120110242.

Ruigrok, E., D. Draganov, M. Gomez, J. Ruzzante, D. Torres, I. Lopes Pumarega, N. Barbero, A. Ramires, A. R. Castano Ganan, K. van Wijk, and K. Wapenaar (2012). Malargüe seismic array: Design and deployment for the temporary array, Eur. Phys. J. Plus 127, doi: 10.1140/epjp/i2012012126-7.

Strollo, A., S. Parolai, K. H. Jäkel, S. Marzorati, and D. Bindi (2008). Suitability of short-period sensors for retrieving reliable $\mathrm{H} / \mathrm{V}$ peaks for frequencies less than $1 \mathrm{~Hz}$, Bull. Seismol. Soc. Am. 98, 671-681, doi: $10.1785 / 0120070055$.

Tsai, N. C. (1970). A note on the steady-state response of an elastic halfspace, Bull. Seismol. Soc. Am. 60, 795-808.

Witte, J., and S. L. Periale (2008). New Aspects on Tertiary thick-skinned thrust geometries related to inherited Permo-Triassic extensional faults in the Bardas Blancas area, Neuquen basin, paper presented at VII Congreso de Exploracion y Desarrollo de Hidrocaburus, Buenos Aires, Argentina, 3-8 November 2008.

Yohei Nishitsuji

Elmer Ruigrok

Deyan Draganov

Department of Geoscience and Engineering Delft University of Technology

Stevinweg 1/P.O. Box 5048 2628 CN Delft/2600 GA Delft

The Netherlands

y.nishitsuji@tudelft.nl

Martin Gomez

International Center for Earth Sciences (ICES)

Comision Nacional de Energia Atomica (CNEA)

Avda. Gral. Paz 1499

Buenos Aires, Argentina 